
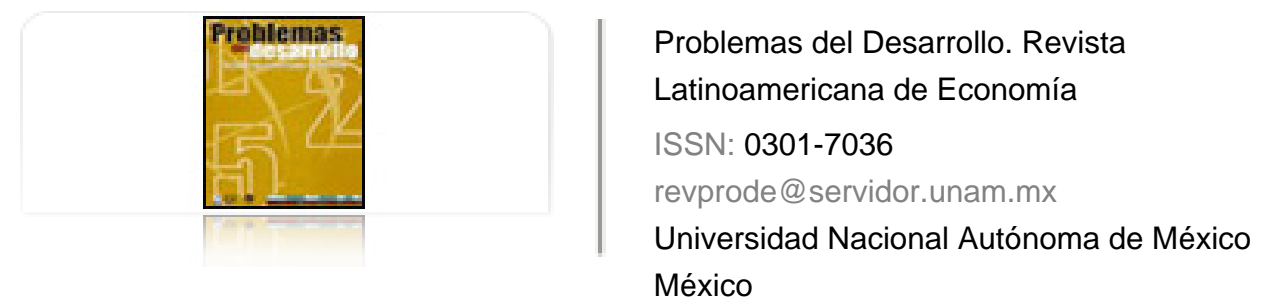

Garrido Noguera, Celso; Ortiz Guerrero, Claudia

De crisis en crisis: la evolución reciente de las grandes empresas mexicanas

Problemas del Desarrollo. Revista Latinoamericana de Economía, vol. 40, núm. 156, enero-marzo, 2009, pp. 47-75

Universidad Nacional Autónoma de México

Distrito Federal, México

Disponible en: http://www.redalyc.org/articulo.oa?id=11820096007

- Cómo citar el artículo

- Número completo

- Más información del artículo

Página de la revista en redalyc.org

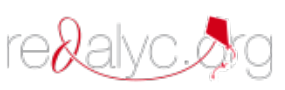

Sistema de Información Científica

Red de Revistas Científicas de América Latina, el Caribe, España y Portugal Proyecto académico sin fines de lucro, desarrollado bajo la iniciativa de acceso abierto 


\title{
DE CRISIS EN CRISIS: LA EVOLUCIÓN RECIENTE DE LAS GRANDES EMPRESAS MEXICANAS
}

\author{
Celso Garrido Noguera* \\ Claudia Ortiz Guerrero**
}

Fecha de recepción: 30 de octubre de 2008. Fecha de aceptación: 28 de enero de 2009.

\section{Resumen}

La economía y las compañías mexicanas se enfrentan otra vez a una crisis que repercutirá en al país con efectos y alcances aún desconocidos, debido a que es una crisis de la mundialización económica. En ese contexto, se analizan las grandes empresas manufactureras mexicanas (GEM), a casi 20 años de que iniciaran los cambios en el marco de la nueva organización económica nacional con las reformas de los noventa. El estudio muestra que esa organización y las GEM tienen graves limitaciones estructurales para contender con la competencia global y la presente crisis en particular. Se destaca la urgente necesidad de que el gobierno y las GEM realicen acciones para modernizar la economía nacional y estimular competencias de largo plazo con base en la innovación y el conocimiento, junto a una integración real y sólida de las pequeñas y medianas empresas (PYME) en las cadenas productivas.

Palabras clave: crisis, mundialización, grandes empresas, cambio económico y desarrollo.

* Profesor-investigador del Departamento de Economía, Universidad Autónoma Metropolitana Azcapotzalco. Correo electrónico: garridocelso@ hotmail.com.

** Profesora-investigadora del Departamento de Producción Económica, Universidad Autónoma Metropolitana Xochimilco. Correo electrónico: cortiz@ correo.xoc.uam.mx.

Los autores agradecen la eficaz tarea de Roberto Enríquez con referencia a la búsqueda y elaboración de la base de datos estadística. 
Abstract

Mexico's economy and its companies again face a crisis that will have repercussions on the country with effects whose nature and extent are yet unknown, given that this is a crisis of economic globalization. In this context, we analyze Mexico's large manufacturers (MLM), nearly 20 years since changes in the framework of the new national economic organization began with the reforms of the 1990s. The study shows that this organization and the MLM have serious structural limitations to compete globally and in the present crisis in particular. It stresses the urgent need that the government and the MLM carry out actions to modernize the national economy and stimulate long-term competitiveness based on innovation and know-how, together with a real and solid integration of small and medium-sized companies (PYME) in the productive chains.

Key words: crisis, globalization, large companies, economic change and development.

\section{Résumé}

L'économie et les sociétés mexicaines s'affrontent de nouveau à une crise qui se répercutera dans le pays avec des effets et une portée encore ignorés du fait que c'est une crise de la mondialisation de l'économie. Dans ce contexte, cet article analyse les grandes entreprises manufacturières mexicaines (GEM), presque vingt ans après leurs premiers changements dans le cadre de la nouvelle organisation économique mondiale avec les réformes des années 90. L'étude montre que cette organisation et les GEM ont de graves handicaps structurelles pour contenir la concurrence globale et la crise actuelle en particulier. Il en ressort qu'il y a un besoin urgent d'actions du gouvernement et des GEM pour moderniser l'économie nationale et stimuler l'acquisition de compétences à long terme sur la base de l'innovation et de la connaissance, conjointement à une intégration sociale réelle et solide des petites et moyennes entreprises (PYME) dans les chaînes productives.

Mots clés: crise, mondialisation, grandes entreprises, changement economique et développement.

\section{Resumo}

A economia e as companhias mexicanas enfrentam outra vez uma crise que repercutirá no país com efeitos e alcances ainda desconhecidos, devido a que é uma crise da globalização econômica. Nesse contexto se analisam as grandes empresas manufatureiras mexicanas (GEM), há quase 20 anos em que iniciaram as mudanças no marco da nova organização econômica nacional com as reformas dos noventa. O estudo mostra que essa organização e as GEM têm graves limitações estruturais para contender com a concorrência global e a presente crise em particular. Destaca-se a urgente necessidade de que o governo e as GEM realizem ações para modernizarem a economia nacional $e$ estimularem concorrências de longo prazo com base na inovação e no conhecimento, junto a uma integração real e sólida das pequenas e medias empresas (PYME) nas correntes produtivas.

Palavras chave: crise, globalização, grandes empresas, câmbio econômico e desenvolvimento.

\section{Desarrollo}




\section{Introducción}

$\mathcal{L}$

a economía y las empresas de México confrontan nuevamente una crisis de grandes proporciones, pero a diferencia de las de 1982 y 1994, que se inicia-

ron en el país para expandir sus efectos a la economía internacional, ahora el fenómeno se da a la inversa. La actual es la primera gran crisis de la llamada mundialización económica, ${ }^{1}$ que causará impacto a la economía y a la sociedad mexicana con efectos cuya magnitud no es posible definir aún. Sin embargo, es evidente que ello será resultado de la interrelación entre la acción de aquellas fuerzas externas desequilibrantes y las condiciones en las que la economía mexicana y sus distintos actores y componentes arriban a esta situación, en un proceso de múltiples dimensiones y de interacciones complejas. Para contribuir a la comprensión de un ángulo de esos factores internos en este trabajo se analiza la situación desde donde enfrentarán la actual crisis las GEM, vistas en el marco de las condiciones de la economía nacional. A partir de ello se hacen consideraciones y propuestas ante los previsibles desafíos que surgirán para el futuro de estas corporaciones.

Para ello se parte de la premisa de que tanto esta crisis internacional como la situación actual de la economía y las GEM representan el primer gran ajuste en el proceso de cambios desatados con las reformas mediante las cuales se implantaron políticas para transformar la organización de las economías hacia la liberalización y desregulación de los mercados, aplicadas e impulsadas en el ámbito internacional por la llamada contrarrevolución conservadora de Ronald Reagan y Margaret Thatcher, en América Latina con el Consenso de Washington; y en México en el gobierno de Carlos Salinas de Gortari, en cuyo contexto las GEM transformaron su configuración y desempeño estratégico hacia una lógica de competencia global. El presente estudio se ocupa de explorar, desde el ángulo de las GEM, los alcances y limitaciones de los cambios ocurridos durante este periodo, tanto en la organización económica nacional como en las propias empresas, para reflexionar a partir de ello sobre los desafíos que se presentan a las GEM y al país ante la actual crisis, así como las posibilidades para enfrentarla desde la perspectiva del desarrollo nacional.

En este estudio se argumenta la hipótesis de que los cambios ocurridos desde los noventa en la organización económica nacional y en las GEM no han conducido a generar configuraciones efectivas para enfrentar la competencia global y la actual crisis, ni en el nivel agregado ni en el sectorial manufacturero y mucho menos en el ámbito

$1 \quad$ Véase Chesnais, 1999. 
de esas GEM que constituyen el centro de nuestro interés. Por ello, no sólo cabe esperar impactos severos por la crisis, sino que de persistir la actual organización económica y las políticas que la orientan, se ampliará la brecha entre la evolución de la economía y las GEM en México, respecto a las tendencias de cambio que son esperables en la economía mundial a la salida de la presente crisis. En consecuencia, es necesario promover que las políticas públicas superen el enfoque anticíclico con que se funda el presupuesto 2009, para asumir una acción enérgica en la dirección del cambio económico que logre potenciar la competitividad nacional basada en la promoción de la economía de la innovación, el conocimiento y el impulso hacia una creciente articulación entre la inserción internacional competitiva y un sólido mercado interno, todo ello al tiempo que se impulsa la transformación de los portafolios de las GEM hacia nuevos modelos basados en innovación asociados a PYME dinámicas, para generar con todo ello una dinámica creciente y sostenible del empleo y el ingreso per capita de los mexicanos.

Para argumentar esa hipótesis primero se analiza la evolución de la economía nacional en el nivel agregado y en el sector manufacturero durante el periodo 19902008, luego se considera el desempeño de las GEM, con base en una muestra conformada con información de la Bolsa Mexicana de Valores (BMV). Finalmente, se reflexiona sobre los desafíos y posibilidades para enfrentar la actual crisis desde el ángulo del desarrollo económico nacional.

\section{Los cambios en la organización económica nacional y la fragilidad de la misma ante la crisis}

A comienzos de los años noventa del siglo pasado, con Carlos Salinas de Gortari como presidente y en el marco de las estrategias del llamado Consenso de Washington, ${ }^{2}$ en México se aplicó un conjunto de políticas que transformarían radicalmente la organización económica nacional. Así, el país pasó de operar como una economía cerrada bajo una fuerte intervención del Estado en los precios y los mercados, hacia una economía abierta, desregulada, en la que la asignación de los recursos económicos se operaría desde la acción de las empresas privadas en condiciones de competencia. En este nuevo contexto, los actores determinantes serían las empresas extranjeras con inversiones en el país y las GEM, particularmente del sector manufacturero, mientras que la dinámica de la economía estaría dada por la evolución del comercio exterior, a partir de una nueva inserción del país en la economía internacional, y particularmente

2 Véase Williamson, 1989. 
Gráfica 1

Exportaciones totales y manufactureras

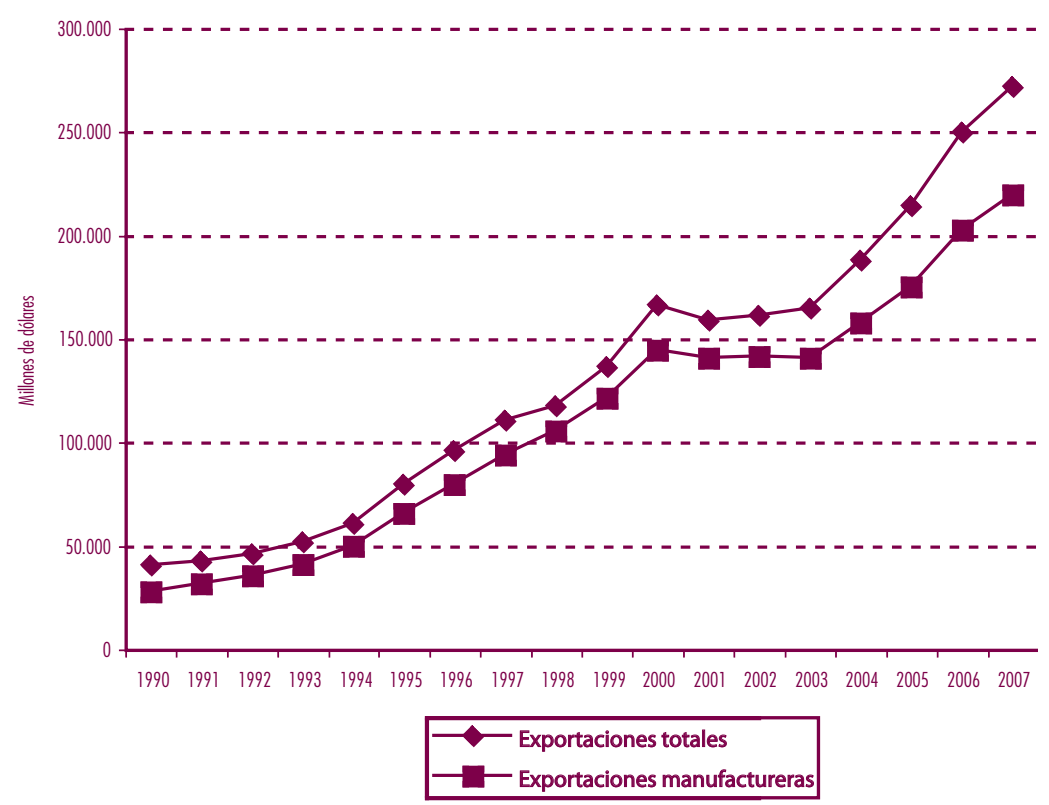

Fuente: Elaboración propia con base en BANXICO (2008).

en relación con la de Estados Unidos, en un intensivo comercio manufacturero, dando lugar a lo que algunos autores denominaron como economía maquiladora. ${ }^{3}$

Tales reformas estaban encaminadas a crear poderosos incentivos para el desarrollo de la economía y sus actores. Pero a casi 20 años de iniciado el proceso, los resultados son extremadamente problemáticos, pues si bien se lograron algunas de las metas propuestas, al mismo tiempo el cuadro conjunto de la organización económica nacional muestra fuertes desequilibrios, tanto en el nivel agregado como en el sector manufacturero, y se observa que la nueva organización económica no propició un entorno positivo y sostenible para el desarrollo de las empresas nacionales en general y tampoco de las GEM. Unas pocas evidencias permiten apoyar esta afirmación.

Cabe destacar en primer lugar que el nuevo orden económico registró un éxito extraordinario en el desarrollo de la actividad exportadora de manufactura que era su gran objetivo estratégico, superando con ello el predominio que en el periodo previo había alcanzado el petróleo en las exportaciones, como se observa en la gráfica 1.

\footnotetext{
3 Véase, por ejemplo, Katz, 2007.
} 
Sin embargo, un análisis detallado del comportamiento de la balanza comercial muestra un cuadro extremadamente preocupante como se observa en la gráfica 2.

Gráfica 2

Balances del comercio exterior

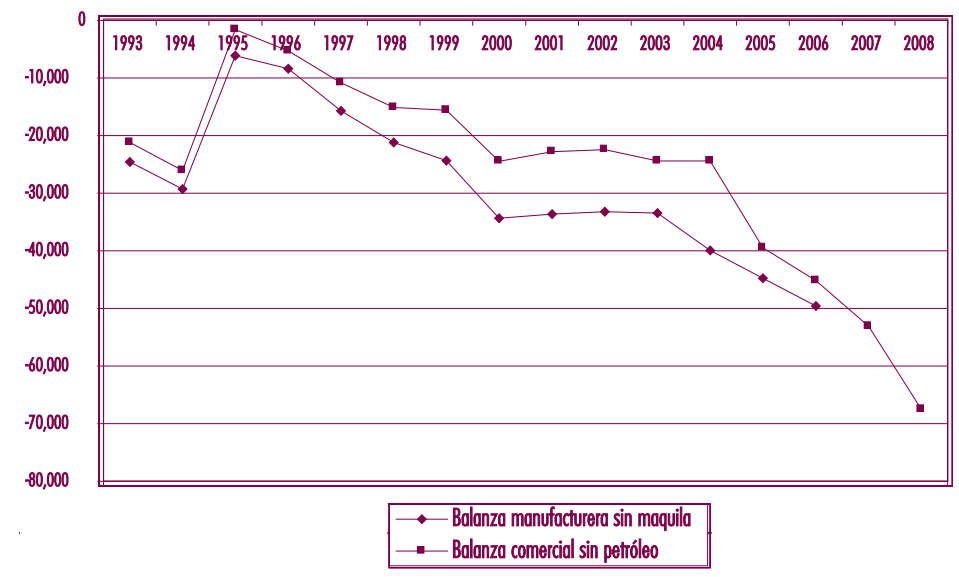

Fuente: Elaboración propia con base en BANXICO (2008).

De una parte, el saldo negativo del conjunto del comercio exterior, excluyendo el petróleo, ha crecido de manera acelerada hasta alcanzar valores del orden de los 70 mil millones de dólares (mmd), más que duplicando los desequilibrios previos a la crisis de 1995. Pero lo más preocupante es que dicho déficit aparece explicado básicamente por los desequilibrios del comercio externo manufacturero neto del comercio de las maquiladoras, que para 2006 alcanzaba cifras del orden de los 50 mmd.

Esta situación deficitaria externa pudo sostenerse a lo largo del periodo gracias a la concurrencia de los superávit en la cuenta de capitales como se observa en la gráfica 3 , los altos precios del petróleo y las remesas que llegaron a alcanzar valores anuales del orden de los 25 mmd en 2007.

Como se puso en evidencia durante 2008, esos favorables factores para financiar los desequilibrios comerciales externos están revirtiendo su tendencia, con lo que se puede esperar que en el curso de 2009 y los años siguientes se presenten tensiones por las dificultades para financiar dichos desequilibrios o por la inestabilidad cambiaria que se pueda generar.

Aun con las tensiones mencionadas, puede señalarse que el comercio exterior tuvo un notable incremento a partir de las reformas económicas, lo que sin embargo se hizo a costa de mantener al mercado interno en condiciones de estancamiento, tal

\section{Desarrollo}


Gráfica 3

Balance de la cuenta de capitales

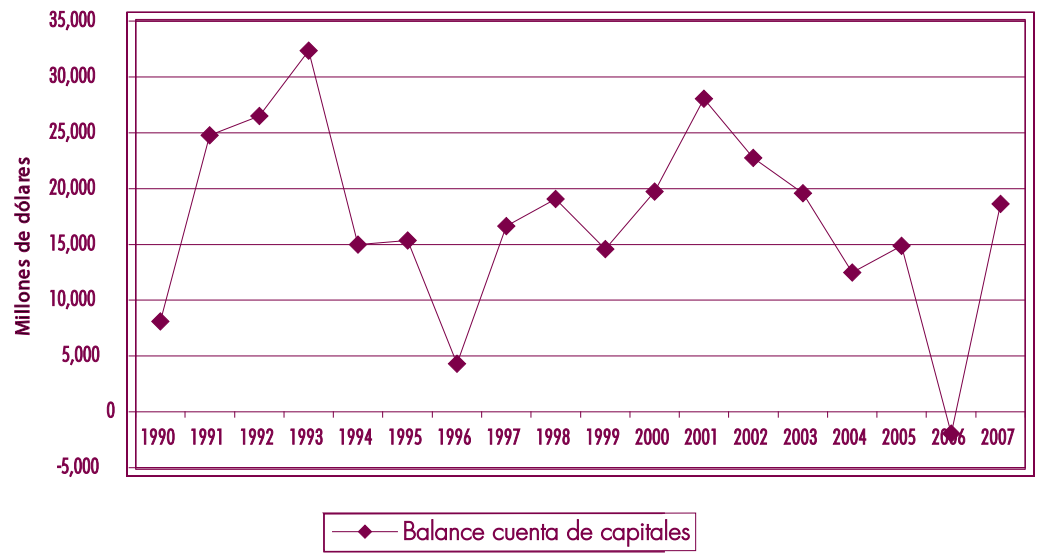

Fuente: Elaboración propia con base en BANXICO (2008).

Gráfica 4

Evolución de la estructura de la demanda agregada

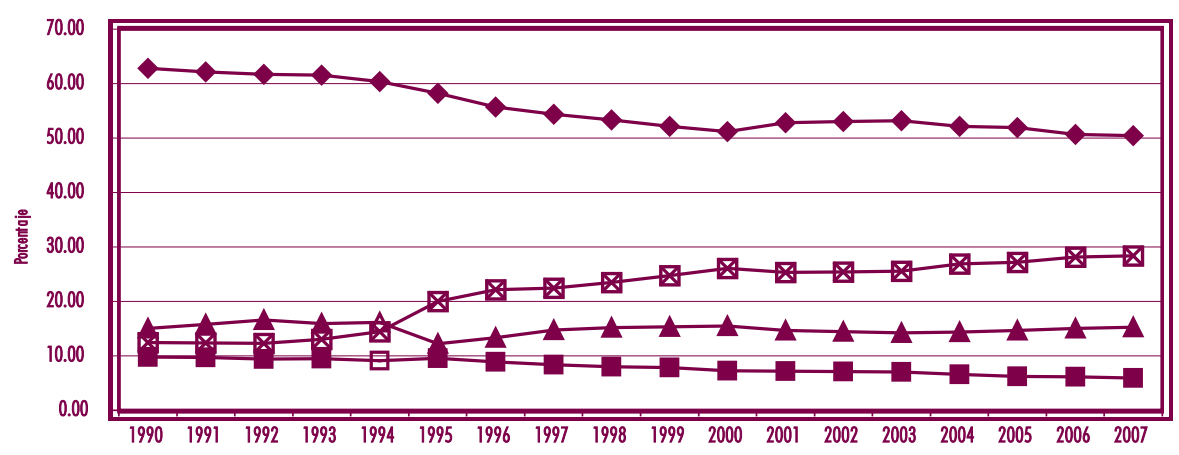

$$
\begin{aligned}
& \longrightarrow \text { Consumo privado } \\
& \longrightarrow \text { - Consumo gobierno } \\
& \rightarrow-\text { FCFF } \\
& \longrightarrow \text {-Exportaciones }
\end{aligned}
$$

Fuente: Elaboración propia con base en BANXICO (2008).

como lo muestra el análisis de la demanda y la oferta agregada. Con respecto a la primera, puede verse la evolución de sus componentes en la gráfica 4.

La lógica de la nueva organización económica surgida de la reforma hizo que el componente expansivo de la demanda agregada fueran las exportaciones en general, y particularmente las manufactureras, mientras que el consumo privado y de gobierno cayeron de manera consistente a lo largo del periodo, y la formación bruta de capital 
Gráfica 5

Evolución de la estructura de la oferta agregada

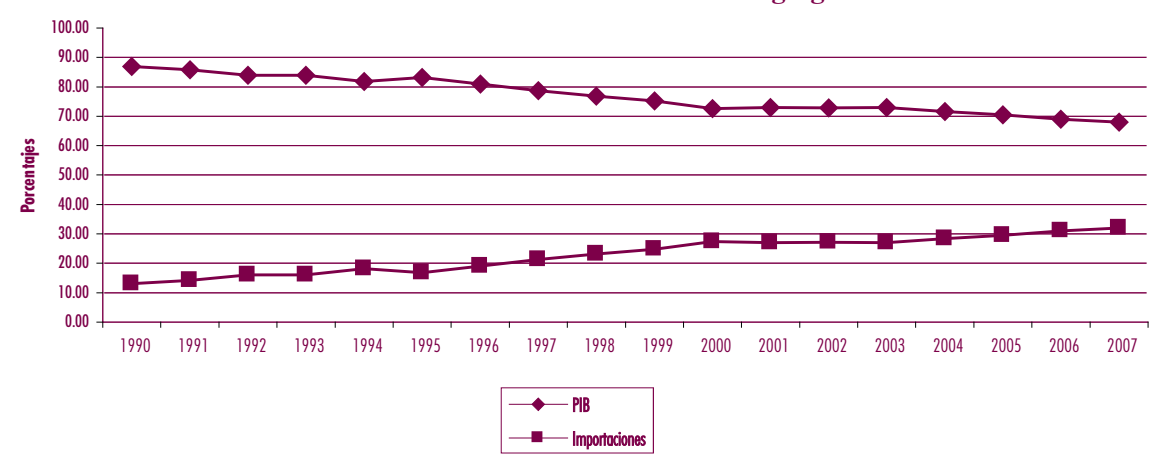

Fuente: Elaboración propia con base en BANXICO (2008).

fijo (FBCF) se mantuvo estancada en ese lapso. La otra cara de ello lo muestra la evolución de los componentes de la oferta agregada, cuando se comprueba el sacrificio de la producción local en beneficio de los productos importados, de lo que se informa en la gráfica 5.

En el periodo de análisis, las importaciones se constituyeron en una parte creciente de la oferta agregada, mientras la producción local medida, vía el producto interno bruto (PIB), cayó de forma consistente.

Ello sugiere que la estrategia de promover que la dinámica del nuevo orden económico estuviera dada por la evolución de las exportaciones manufactureras realizadas, con base en importaciones temporales —inducidas por el sistema de incentivos creados mediante políticas públicas-, y provocara una desarticulación del aparato productivo del país. ${ }^{4}$ En la literatura de inspiración cepalina se caracteriza como la configuración de una economía maquiladora. ${ }^{5}$

Esta desfavorable transformación del aparato productivo en el curso de las reformas también se manifiesta al analizar la evolución durante estos años del PIB manufacturero y total, como se observa en la gráfica 6.

El PIB manufacturero ha tenido un comportamiento cíclico con fluctuaciones y bajas tasas de crecimiento, que sigue la evolución y la variación de las tasas del PIB total, aunque se observa que tanto en las fases de expansión como de contracción

4 Estos incentivos consistieron, por una parte, en los de naturaleza fiscal con programas como Pitex y Altex, y por la otra en el que ofrece la formación de un tipo de cambio sobrevaluado que reduce el costo de dichas importaciones temporales.

5 Véase por ejemplo Katz, 2007.

\section{Desarrollo}


Gráfica 6

PIB total y manufacturero

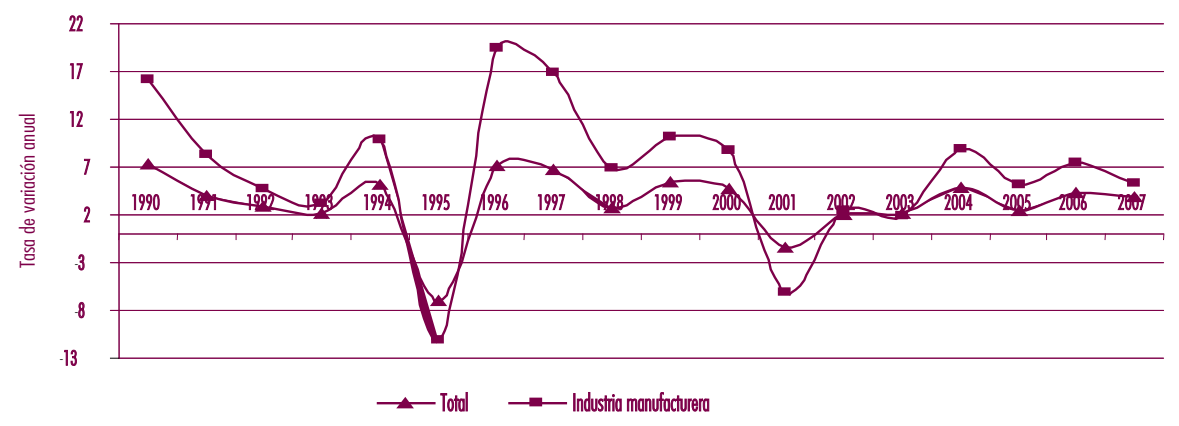

Fuente: Elaboración propia con base en INEGI (2008).

la variación del PIB manufacturero excede la de aquel PIB total, mostrando una respuesta más que proporcional en la expansión o la contracción. Ello sugiere un férreo comportamiento procíclico de aquel PIB manufacturero, en directa correlación con la dinámica del mercado interno, que es la base de la actividad económica nacional.

Lo anterior muestra que con la nueva organización económica nacional la actividad industrial cumple un proceso inestable que es desfavorable para la actividad de las empresas en general y, en particular, para las GEM que nos ocupan. ${ }^{6}$ Además puede señalarse que tales comportamientos del PIB manufacturero y del PIB total indican que luego de las reformas la economía mexicana no ha logrado un sendero sostenible de crecimiento de largo plazo. Por el contrario, sigue operando con una dinámica de ciclos de corto plazo, como lo indican las breves expansiones de 19901994, 1996-1997 y 2003-2004, interrumpidas por crisis profundas como las de 1995 y 2001, y la actual iniciada en 2008, aún en curso. Los efectos desfavorables de la nueva organización económica sobre la manufactura se confirman al observar, con base en la información de los Censos Económicos, la evolución manufacturera du-

6 Como nota marginal cabe señalar que este comportamiento de ciclos cortos da continuidad a una dinámica de la economía nacional que se registra desde 1976, con la particularidad de que parecen haber cambiado los determinantes de los ciclos, y que en 1976-1995 éstos se asociaban con la pugna por el control del excedente con hitos sexenales, mientras que en 2001 y en la actual crisis el fenómeno está determinado por el comportamiento de la economía global, frente a la cual el país muestra gran vulnerabilidad bajo las condiciones en las que se integró a la misma con las reformas. Para un análisis de la dinámica cíclica tradicional puede verse Garrido, 2005. 
Cuadro 1 Participación relativa de establecimientos y empleo manufacturero en el total

\begin{tabular}{|c|c|c|c|c|c|c|c|c|}
\hline & \multicolumn{8}{|c|}{ Unidades económicas } \\
\hline & \multicolumn{2}{|l|}{1988} & \multicolumn{2}{|c|}{1993} & \multicolumn{2}{|l|}{1998} & \multicolumn{2}{|l|}{2003} \\
\hline & Absolutos & $\%$ & Absolutos & $\%$ & Absolutos & $\%$ & Absolutos & $\%$ \\
\hline Total nacional & $1,316,952$ & 100 & $2,512,631$ & 100 & $2,801,374$ & 100 & $3,005,157$ & 100 \\
\hline Manufacturas & 141,446 & 10.74 & 265,427 & 10.56 & 344,118 & 12.28 & 409,052 & 13.61 \\
\hline \multirow[t]{4}{*}{ Resto de Sectores } & $1,175,506$ & 89.26 & 2,247,204 & 89.44 & $2,457,256$ & 87.72 & $2,596,105$ & 86.39 \\
\hline & \multicolumn{8}{|c|}{ Personal Ocupado } \\
\hline & \multicolumn{2}{|l|}{1988} & \multicolumn{2}{|l|}{1993} & \multicolumn{2}{|l|}{1998} & \multicolumn{2}{|l|}{2003} \\
\hline & Absolutos & $\%$ & Absolutos & $\%$ & Absolutos & $\%$ & Absolutos & $\%$ \\
\hline Total nacional & $10,143,312$ & 100 & $13,057,490$ & 100 & $13,596,761$ & 100 & $16,39,536$ & 100 \\
\hline Manufacturas & $2,705,696$ & 26.67 & $3,246,042$ & 24.86 & $4,232,322$ & 31.13 & $4,198,579$ & 25.85 \\
\hline Resto de sectores & $7,437,616$ & 73.33 & $9,811,448$ & 75.14 & $9,364,439$ & 68.87 & $12,040,957$ & 74.15 \\
\hline
\end{tabular}

Fuente: Elaboración propia con base en Censos Económicos, INEGI (varios años).

rante el periodo, en lo que se refiere a la importancia relativa de los establecimientos y el empleo en dicho sector con respecto al total de éstos y puestos laborales en la economía, lo cual se informa en el cuadro $1 .^{7}$

Según se observa en este cuadro, la participación relativa de los establecimientos que operan en el sector manufacturero crece en tres puntos porcentuales respecto al total de los mismos en la economía nacional, lo que indica que marcha en el sentido inverso al descenso relativo del PIB manufacturero. En contraste, la participación del empleo manufacturero en el empleo total decrece en un punto porcentual, menor que la caída de dos puntos en la participación del PIB manufacturero respecto al PIB total antes mencionado. Ello se explica por el acelerado crecimiento de los microestablecimientos manufactureros, que en principio pueden ubicarse dentro de los rangos de actividades de autoempleo.

Para comprender mejor la evolución de la actividad manufacturera se consideran ahora sólo los pequeños, medianos y grandes establecimientos en el cuadro 2.

En el caso de los pequeños establecimientos, se observa un ligero aumento en su número relativo junto a una reducción en la participación relativa del empleo que

7 Para compensar los cambios en las definiciones oficiales sobre tamaño de establecimientos, en esta información se ha normalizado su dimensión de acuerdo con las actuales definiciones en el respectivo decreto oficial. 
Cuadro 2

Establecimientos manufactureros pequeños, medianos y grandes

\begin{tabular}{|c|c|c|c|c|c|c|c|c|c|}
\hline \multirow{5}{*}{$\begin{array}{l}\text { Pequeñas } \\
\text { Medianas } \\
\text { Grandes }\end{array}$} & \multicolumn{4}{|c|}{ Establecimientos } & & \multicolumn{4}{|c|}{ Personal ocupado } \\
\hline & \multirow{2}{*}{$\begin{array}{l}1988 \\
65.11\end{array}$} & \multicolumn{2}{|c|}{$\begin{array}{c}1993 \quad 1998 \\
\text { Porcentaje }\end{array}$} & \multirow{2}{*}{$\begin{array}{l}2004 \\
66.45\end{array}$} & \multirow{4}{*}{$\begin{array}{l}\text { Pequeñas } \\
\text { Medianas } \\
\text { Grandes }\end{array}$} & \multirow{2}{*}{$\begin{array}{l}1988 \\
15.00\end{array}$} & \multicolumn{2}{|c|}{$\begin{array}{r}1993 \quad 1998 \\
\text { Porcentaje }\end{array}$} & \multirow{2}{*}{$\begin{array}{l}2004 \\
12.56\end{array}$} \\
\hline & & 75.40 & 66.88 & & & & 25.20 & 14.44 & \\
\hline & 26.42 & 14.30 & 24.20 & 24.30 & & 28.50 & 19.40 & 26.50 & 23.57 \\
\hline & 8.47 & 10.30 & 8.92 & 9.25 & & 56.50 & 55.40 & 59.06 & 63.86 \\
\hline & \multicolumn{4}{|c|}{ Producción bruta } & & \multicolumn{4}{|c|}{ Valor agregado } \\
\hline & 1988 & $\begin{array}{r}1993 \\
\text { Por }\end{array}$ & $\begin{array}{l}1998 \\
\text { antaje }\end{array}$ & 2004 & & 1988 & 1993 & $\begin{array}{l}1998 \\
\text { rcentaje }\end{array}$ & 2004 \\
\hline Pequeñas & 7.67 & 15.40 & 14.44 & 5.86 & Pequeñas & 6.23 & 15.70 & 6.60 & 5.70 \\
\hline Medianas & 21.86 & 16.00 & 26.50 & 17.96 & Medianas & 20.25 & 15.40 & 21.88 & 17.36 \\
\hline Grandes & 70.46 & 68.60 & 59.06 & 76.18 & Grandes & 73.52 & 68.90 & 71.52 & 76.94 \\
\hline
\end{tabular}

Fuente: Elaboración propia con base en Censos Económicos, INEGI (varios años).

generan, y en su aportación a la producción bruta y a la creación de valor agregado. ${ }^{8}$ Esto sugiere que ese incremento en número no significa una mayor relevancia en su desempeño económico. A su vez, los establecimientos medianos muestran un retroceso generalizado al registrar tanto una reducción en su número relativo con relación al personal ocupado como en su participación relativa en la producción y en el valor agregado generado. Finalmente, los valores para los grandes establecimientos son crecientes en cuanto a su número relativo y relevantes en el caso del empleo con un incremento de siete puntos, así como en la participación en la producción bruta en la que se expande en seis puntos. En cambio, su participación en el valor agregado crece pero sólo algo más de tres puntos, menos proporcional al incremento del empleo y el producto.

Lo anterior pone en evidencia que este universo de los pequeños, medianos y grandes establecimientos manufactureros ha evolucionado en el sentido de elevar la concentración en favor de los últimos y, en contrapartida, un deterioro relativo a los dos primeros en la actividad manufacturera.

En conjunto, lo visto muestra que paradójicamente bajo la nueva organización económica dominada por la expansión de las exportaciones manufactureras se produce una evolución muy desfavorable de la manufactura, pues cae la importancia

8 El censo de 1993 muestra crecimientos atípicos de los valores para los pequeños establecimientos, lo que sugiere el fuerte carácter procíclico en relación con el mercado interno de estas entidades. Éste es un fenómeno repetidamente observado en este tamaño de establecimiento en distintos países de la región, como puede verse en Peres y Stumpo, 2002. 
relativa del sector respecto al PIB total, y dentro de ello aumenta de manera extraordinaria la presencia de microestablecimientos, mientras que los pequeños y medianos se debilitan, y crece la concentración de la actividad manufacturera en favor de los grandes. Por tanto, el resultado está lejos de lo que cabía esperar con las reformas macroeconómicas, la apertura económica y la nueva integración a la economía internacional. En lugar de tener una masa renovada de campeones competitivos surgiendo del tejido industrial en el segmento de las pequeñas y medianas empresas, el nuevo sistema industrial ha generado una enorme masa de perdedores desde el punto de vista de la competencia internacional: las microempresas, mientras que las PYME no parecen ser fuente de campeones, sino que en conjunto pierden posiciones relativas frente a los grandes establecimientos, aparentemente los ganadores en el cambio industrial desde los noventa.

Una evidencia complementaria sobre la desfavorable evolución de la manufactura la brinda la Encuesta Nacional de Innovación, aplicada en 2002 por el INEGI-CONACYT. Se aplicó a un conjunto de mil 609 empresas de diverso tamaño, tanto nacionales como extranjeras. En la encuesta se reporta que respecto a la pregunta sobre si habían realizado al menos una innovación en el año de referencia, sólo 34\% (542) de las mismas contestó afirmativamente. ${ }^{9}$ A pesar de las limitaciones que ello pueda tener, es un indicador sugerente de un fenómeno económico relevante sobre el cual hay consenso en el país, en cuanto a que la dinámica competitiva de la manufactura en el nuevo orden económico no está basada en la innovación.

Tanto la evolución analizada en el sector externo como en el mercado interno, particularmente la manufactura, se cumplió con base en el sistema de precios macroeconómicos (tasa de interés, tipo de cambio, nivel de precios) generado luego de la crisis de 1995, al que los elaboradores de las políticas presentaron como un rasgo distintivo del nuevo orden. Dichos precios pueden apreciarse en la gráfica 7.

De éstos destacamos en particular el tipo de cambio que durante todo el periodo conoció una sostenida sobrevaluación, con niveles máximos registrados a mediados de 2008. Ello fue resultado de la extraordinaria afluencia de diversos fondos externos, que apreciaron el peso, en el marco de la política de Banco de México (BANXICO), por la cual el tipo de cambio se determina con base en la oferta y la demanda, con el respaldo de un monto extraordinario de reservas. Sin embargo, este régimen mostró sus insuficiencias desde octubre de 2008, cuando el tipo de cambio sufrió una devaluación del orden de $40 \%$, debido a cambios en los distintos flujos financieros inter-

$9 \quad$ Véase Garrido y Padilla-Pérez, 2008. 
Gráfica 7

CETES, tipo de cambio e IPC

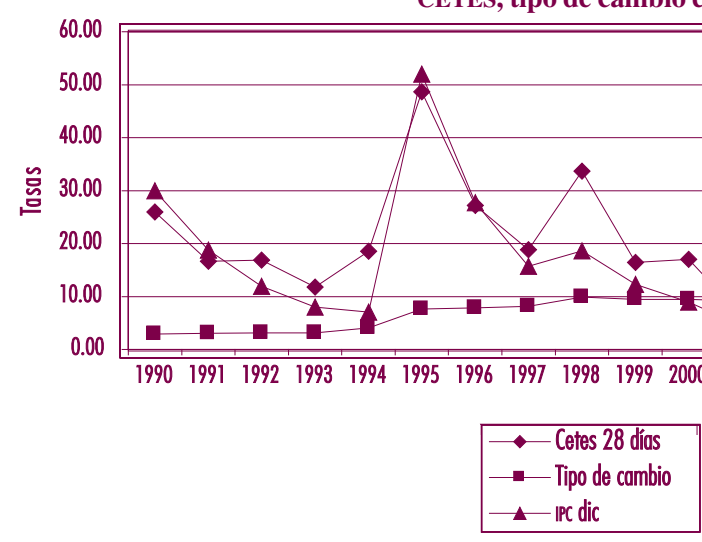

Nota: Con valores hasta noviembre de 2008 .

Fuente: Elaboración propia con base en BANXICO (2008).

nacionales promovidos por la crisis, sin que operara el blindaje de reservas. Lo que ha transmitido un extraordinario desequilibrio en el sector externo y en el mercado interno cuyos efectos aún están curso de manifestarse, pero que sin duda serán de carácter regresivo.

En conjunto, lo analizado confirma la proposición presentada al inicio acerca de que la nueva organización económica nacional, configurada a partir de las reformas iniciadas en 1990, opera con fuertes tensiones y desequilibrios latentes que deterioran el desarrollo manufacturero y condicionan la dinámica de cambio de las GEM que nos ocupan, afectándolas severamente cuando dichos desequilibrios se hacen evidentes como en la actual crisis, según se presenta más adelante.

De modo que en las presentes circunstancias la particular configuración del sector externo se establece como uno de los grandes focos rojos que muestran la vulnerabilidad de la actual organización económica. Al mismo tiempo, se hacen evidentes los efectos negativos de haber debilitado el mercado interno y la estructura de la manufactura, los que ahora tienen capacidad muy limitada para asumir el papel de motor en el crecimiento ante la contracción previsible de las exportaciones. Estas condiciones permiten predecir que de seguir el curso trazado por la organización, el procesamiento de la crisis significará graves perjuicios para la economía y la población del país. 


\section{Transformaciones y desempeño problemático}

\section{de las grandes empresas manufactureras mexicanas}

Desde el punto de vista empresarial nacional, fueron las grandes compañías privadas manufactureras las principales beneficiarias de las grandes transformaciones ocurridas en la organización económica nacional, pues las empresas públicas redujeron notablemente su participación relativa en esa actividad debido a las políticas de privatización. ${ }^{10}$ En el curso de aquellas transformaciones, las GEM debieron asumir cambios relevantes con el fin de enfrentar el desafío extraordinario que les representaba la apertura del sector externo, al serles arrancado el paraguas proteccionista bajo el que se habían formado y crecido durante la industrialización sustitutiva de importaciones (ISI). Un grupo significativo de estas GEM dio respuestas proactivas a ese desafío, ${ }^{11}$ al implantar estrategias complejas que, como resulta previsible, fueron diversas y dependieron de factores como el sector, el tamaño y el tipo de empresa. En general, los resultados de estas estrategias fueron exitosos pero con vulnerabilidades estructurales que se han hecho evidentes en las distintas crisis y también en la actual. Mas allá de las especificidades mencionadas, esta vulnerabilidad de su nueva configuración es resultado de cuatro rasgos comunes a esas distintas estrategias. El primer rasgo lo da el hecho de que debieron actuar bajo las mismas características y condicionantes del contexto nacional, marcado por las inestabilidades cíclicas en el país, lo que generó tensiones y desequilibrios que afectaron la operación de las estrategias de cambio empresarial de las GEM. El segundo corresponde al objetivo de las estrategias, que estuvieron definidas por el propósito general de sobrevivir a los nuevos desafíos de la competencia mediante la búsqueda de un aumento acelerado de tamaño, bajo un modelo complejo en el que se combinó la defensa de sus mercados en el país, la expansión de exportaciones y el desarrollo de la internacionalización productiva. Todo ello con el fin de adquirir una escala y estructura de negocios adecuada para enfrentar a los grandes jugadores globales. Con ello daban respuesta por una parte a una necesidad de crecimiento, largamente bloqueada durante el proteccionismo debido a las limitaciones del mercado interno donde operaban y, por otra, seguían una tendencia de las grandes empresas globales en el ámbito internacional en los noventa, cuando se desarrollaron procesos de fusiones y adquisiciones (FYA) de extraordinarias pro-

10 El otro actor empresarial relevante que se benefició con las reformas fueron las empresas extranjeras, cuyo análisis, sin embargo, escapa a los alcances de este trabajo.

11 Para un análisis detallado de este proceso véase Garrido, 1999. 
porciones, que incrementaron los niveles de concentración en la economía mundial. ${ }^{12}$ El tercero, con sólo una excepción,,$^{13}$ fue que estas GEM decidieron que la búsqueda de crecimiento acelerado la harían desde sus líneas de productos con más fortalezas, como eran los de tipo tradicional que habían desarrollado bajo la ISI. Aunque producidos con tecnologías y procesos actualizados, se trataba de productos de mercados maduros en los que las GEM enfrentarían una dura lucha con competidores globales $\mathrm{y}$, en consecuencia, tendrían grandes dificultades para sostener sus estrategias de crecimiento de manera rentable. El cuarto rasgo decisivo para comprender la dinámica de estas empresas en el periodo y en la actual coyuntura de crisis es que las GEM sostuvieron su crecimiento mediante estrategias financieras basadas en deuda tanto interna como externa, lo que en las distintas crisis y también en la actual habría de manifestarse como un factor grave de vulnerabilidad.

Con este esquema, a continuación se analiza la evolución y trasformación de las GEM en el periodo de análisis, para determinar fortalezas y debilidades con las que éstas enfrentan la actual coyuntura, y esbozar desde aquí algunas tendencias posibles en el desarrollo de las mismas dentro del marco de la actual crisis. Este análisis se hace a partir de agrupar aquellos rasgos en tres grandes temas: el entorno macroeconómico, las evidencias del desempeño de las GEM en relación con los objetivos estratégicos propuestos, y lo referido a los modos financieros con los que cumplieron dichos cambios.

En el entorno macroeconómico cabe recordar que las reformas a la organización económica nacional estaban formuladas con la premisa de que la asignación económica, bajo la lógica de los mercados, generaría una evolución económica eficiente y sostenible para la economía en su conjunto y para las empresas competitivas que operarían en ella. En lugar de ello, la economía mexicana sigue presentando una notable inestabilidad cíclica y manifiesta su vulnerabilidad frente a la dinámica de la economía internacional. A poco de haber comenzado las reformas, estas GEM debieron enfrentar la crisis de 1995, que tuvo impactos severos en sus operaciones, aunque dada su nueva configuración de negocios mostró signos distintos a los que les registraron en $1982 .{ }^{14}$ Cuando se recuperaban de los efectos de esa crisis se pre-

12 Véase UNCTAD, 2000.

13 Nos referimos al caso de Pulsar-Seminis que intentó un desarrollo basado en la innovación dentro de la biotecnología, lo que terminó con la quiebra de la empresa.

14 Hay que recordar que con la crisis de 1982 se produjo la quiebra generalizada de las grandes firmas industriales y de los bancos que de distinto modo tenían relaciones de propiedad entre ellos. En aquella ocasión las empresas industriales perdieron los bancos y fueron rescatadas 
sentó otra en 2001, a partir de los atentados en la Torres Gemelas en Nueva York, lo que marcó también un profundo impacto como se verá más adelante. Finalmente, en 2007 comenzó un nuevo proceso de crisis aún en curso. Todo ello se traduce además en bruscas modificaciones en el sistema de precios macroeconómicos sobre el cual operan las compañías, de lo cual se hizo referencia, de modo que las GEM enfrentaron bruscas devaluaciones, aumentos en el Índice de Precios y Cotizaciones (IPC) y alzas de tasas de interés que les crean desequilibrios y posibilidades de quebrantos. Por otra parte, la evolución exportadora basada en el sacrificio del mercado interno y la persistente dinámica regresiva de las relaciones económico sociales que lo acompañan se convertirían a la postre en un verdadero límite para las propias GEM, pues, a pesar de su internacionalización, mantienen un componte central de sus actividades en el mercado interno, como se analiza más adelante. Así, las contracciones de sus mercados externos, como las que se presentan en la actualidad, son difícilmente compensadas con la expansión de mercados locales. Asimismo, durante el periodo de análisis, la economía y las empresas líderes de la economía global han tenido un acelerado proceso de cambio, tanto por los fenómenos de concentración económica que significaron los gigantescos procesos de FYA en diversas industrias globales como por los acelerados desarrollos basados en la economía del conocimiento que transformaron vertiginosamente los perfiles y las fronteras de la competencia global, lo que se suma a los desafíos que deben resolver estas GEM en la nueva dinámica de negocios multinacionales en la que operan.

En conjunto, todo lo anterior sugiere que el ambiente de alta inestabilidad en la economía nacional y de cambios en las circunstancias internacionales de competencia supedita decisivamente el proceso de cambio de las GEM, pues no se crearon condiciones de sostenibilidad en la nueva organización económica nacional para impulsar una dinámica de articulación virtuosa con los nuevos entornos de competencia productiva en la economía global..$^{15}$

Dentro de este contexto macroeconómico, las GEM cumplieron exitosamente con un primer escalón en el gran objetivo estratégico de incrementar su tamaño a partir

mediante un programa oficial denominada Fideicomiso para el Riesgo Cambiario (FICORCA), mientras que el rescate de los bancos se hizo con la nacionalización de los mismos. A diferencia de ello, en la crisis de 1995 las GEM internacionalizadas tuvieron un impacto menor respecto a su riesgo por deuda en divisas, debido a que tenían activos e ingresos también en divisas, aunque en el proceso varias de ellas pedieron sus brazos financieros.

15 De diversa manera, éste es un problema para el conjunto de los países en América Latina generado con las reformas macroeconómicas de los noventa. Para un análisis relevante de desafíos y posibilidades frente a las actuales circunstancias puede verse CEPAL (2008). 
DE CRISIS EN CRISIS: LA EVOLUCIÓN RECIENTE DE LAS GRANDES EMPRESAS

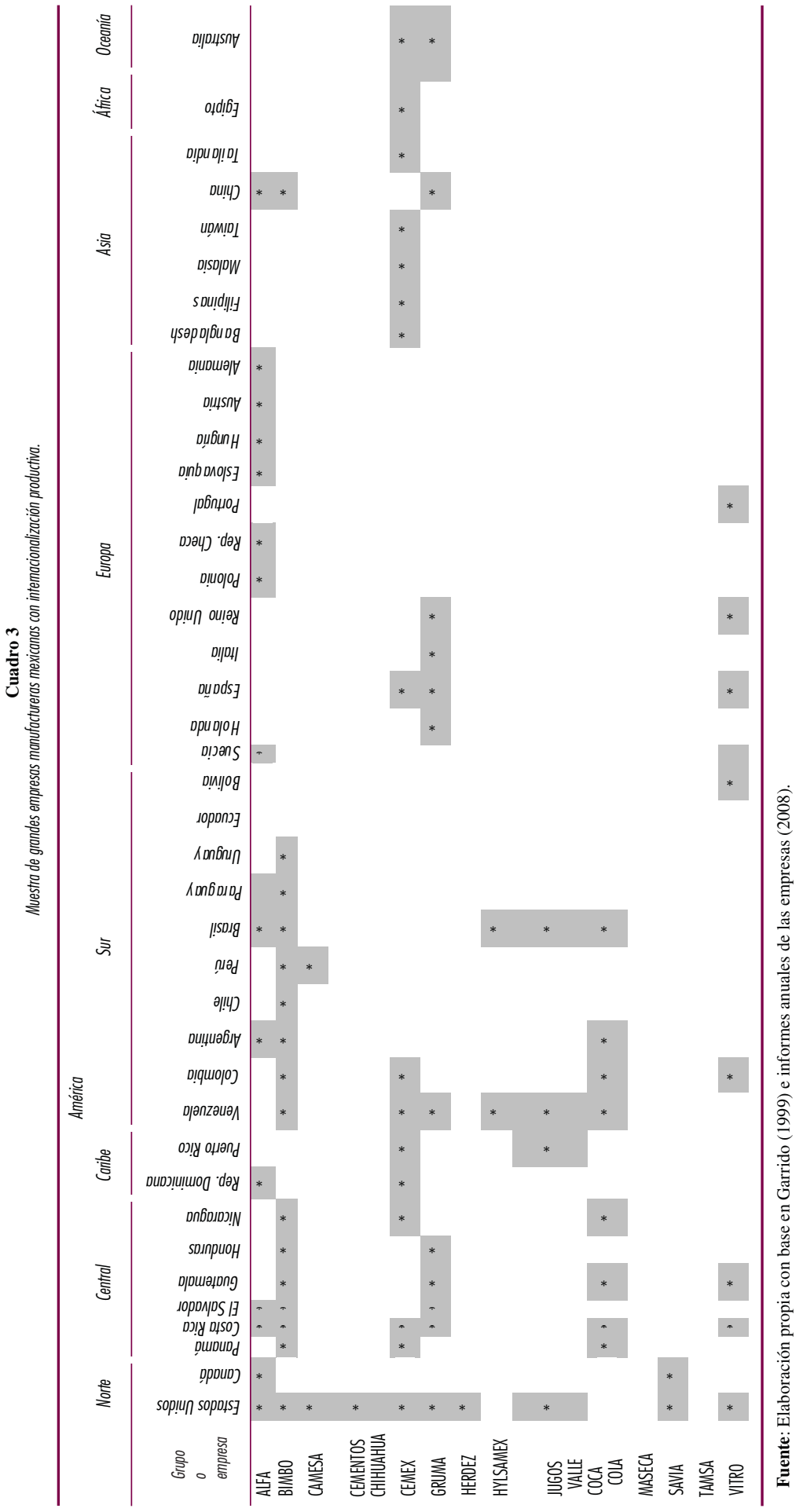


de nuevos modos de participación en la economía internacional, como se comprueba con el hecho de que se transformaron en multinacionales de tamaño medio al lograr internacionalizar su producción con plantas en diversos países. El cuadro 3 es una muestra seleccionada de empresas.

Como se observa en el cuadro, un pequeño pero relevante grupo de GEM se constituyó como empresas multinacionales de alcance regional en el continente americano, y en algunos casos se conformaron como firmas globales en la medida en que están colocadas en dos o más continentes. Esta internacionalización productiva tuvo un comienzo muy acelerado en la primera mitad de los años noventa, pero sufrió una interrupción relativa luego de la crisis de 1994 y volvió a tomar impulso en los últimos años, aunque con distinto ritmo, según cada caso. Hay que destacar que ese proceso de internacionalización de las grandes empresas no fue exclusivo de México, sino que fue una tendencia en un conjunto de países en desarrollo que se incorporaron de manera activa a la economía internacional en los noventa, lo que ha dado lugar al surgimiento de lo que se denominan las multinacionales del sur. ${ }^{16}$ Lo sobresaliente de las GEM mexicanas que se internacionalizaron es que en general se han mantenido en operación de manera independiente, mientras que en casi todos los otros casos en la región las firmas que se internacionalizaron fueron compradas por transnacionales de países desarrollados.

Este proceso no fue lineal y el logro de esa nueva configuración de negocios significó para las GEM el haber construido capacidades estratégicas que les permitieran expandirse en un nuevo sendero de crecimiento de largo plazo. Lo primero, porque no todas las firmas lograron la meta de sobrevivir en esta transformación, ya sea manteniendo su operación como empresas o logrando preservar la propiedad de la misma de manera independiente. En el curso de los noventa varias de estas compañías finalizaron en la quiebra, como DINA y Synkro. El caso más dramático desde un punto de vista del desarrollo económico fue el del grupo Pulsar-Seminis-Savia, ya que era el único conglomerado mexicano con una vocación explícita de basar su competitividad en la innovación y la economía del conocimiento, en particular la biotecnología, lo que no logró debido a la presión de obligaciones por el sobreendeudamiento con que se financió su expansión internacional. ${ }^{17}$ En otros casos el proceso se resolvió con la transferencia del paquete accionario de control a manos extranjeras, como fueron TAMSA e HYLSAMEX, que pasaron a la propiedad del conglomerado ítalo-argentino Techint.

16 UNCTAD, op. cit.

17 Para un análisis del caso Pulsar véase Garrido, 1999. 
Con respecto a las fortalezas y debilidades de las GEM para desarrollar senderos de crecimiento de largo plazo bajo su nueva organización de negocios, se puede tener una primera evaluación al analizar en qué medida su desempeño representa el logro del gran objetivo propuesto en sus estrategias como era incrementar el tamaño de las mismas. Para ello consideramos ahora una muestra de 27 empresas que han cotizado de manera continua en la Bolsa Mexicana de Valores desde 1991 a la fecha. ${ }^{18}$

$\mathrm{Al}$ respecto puede decirse que entre 1990 y 2007 hubo cambios muy importantes aunque diferenciales en el tamaño de las empresas de la muestra medidos por sus ingresos operativos, lo que se tradujo en una modificación de la importancia relativa de las mismas dentro de este universo, como puede verse en el cuadro $4 .{ }^{19}$

Asimismo, se observa en general un importante aumento en el patrimonio neto de estas empresas, según se reporta en el cuadro 5.

Como se aprecia en el cuadro, algunas empresas tuvieron incrementos notables de patrimonio como Ichb, Bimbo o Coca Cola, mientras que otras sufrieron reducciones como en los casos de Vitro, Qumma o Parras.

Para evaluar el resultado obtenido con la estrategia centrada en el aumento de tamaño de las empresas en el cuadro 6 se muestra la rentabilidad promedio de la inversión durante el periodo 1994-2007, ${ }^{20}$ pues ésta resulta ser un indicador central de desempeño para la estrategia y se la relaciona con la variación en ingresos y patrimonio, así como con el grado de participación en los mercados internacionales, para señalar factores explicativos de los casos exitosos según la rentabilidad.

18 Construir esta muestra fue problemático por el hecho de que varias empresas dejan de cotizar en la bolsa a lo largo de estos años. Ello responde a los mencionados procesos de quiebras o fusiones pero también es consecuencia de que las empresas evolucionan al financiarse vía deuda, y en consecuencia retiran sus acciones de la cotización pública. En resumen, la muestra con la que trabajamos está compuesta por 27 firmas del sector manufacturero conforme a la clasificación North American Industry Classification System (NAICS), elaborada conjuntamente por el U.S. Economic Classification Policy Comité (ECPC), Statistics Canada y el Instituto Nacional de Estadística, Geografía e Informática (INEGI), para contar con mayor nivel de comparabilidad de las estadísticas en los países de América del Norte, http://www.census.gov/eos/www/naics/. De acuerdo con la clasificación NAICS, las empresas de la muestra sí están dentro de la clasificación de las manufacturas 31-33, las que reportaron de manera continua a la BMV entre 1991 y 2008. Esta clasificación no coincide con la de la BMV, ya que esta última clasifica a algunas de las firmas incluidas en la muestra en los sectores de Construcción y Otras.

19 El cuadro tiene un sesgo en 1990, porque hay empresas subcalificadas debido a que no se dispone de la información sobre sus ingresos para ese año, por lo que se registran como datos no disponibles (nd).

20 Se toma a partir de 1994, porque se carece de información para todas las empresas en los años previos. De todas maneras se informa de los datos para 1991, en los casos en que están disponibles porque permite apreciar la magnitud de esos cambios desde el inicio de las reformas. 


\begin{tabular}{|c|c|c|c|c|c|c|c|}
\hline \multicolumn{8}{|c|}{ CELSO GARRIDO NOGUERA Y CLAUDIA ORTIZ GUERRERO } \\
\hline & Ranking & & & & & & Ranking \\
\hline Empresa & 1994 & 1990 & 1994 & 1995 & 2001 & 2007 & 2007 \\
\hline CEMEX & 3 & 1304.4 & 3052.1974 & 2593.3 & 7171.6 & 21681.5 & 1 \\
\hline AlFA & 2 & 2236.7 & 2681.7208 & 2816.3 & 4866.5 & 9787.1 & 2 \\
\hline GMDELO & 21 & nd & 1821. 828 & 1264.0 & 3518.7 & 6678.0 & 3 \\
\hline BIMBO & 4 & 1023.9 & 1773.7003 & 1329.3 & 3618.6 & 6622.9 & 4 \\
\hline COCA COLA & 23 & nd & 891.2041 & 737.9 & 1731.2 & 6344.2 & 5 \\
\hline GRUMA & 6 & 659.8 & 1160.2064 & 1001.9 & 1957.5 & 3281.1 & 6 \\
\hline VITRO & 1 & 2635.8 & 4176.521 & 1778.5 & 2525.6 & 2619.3 & 7 \\
\hline ICHB & 16 & 42.5 & 52.3815 & 56.6 & 306.6 & 2518.1 & 8 \\
\hline AHMSA & 20 & nd & 1037.9418 & 1018.0 & 1133.0 & 2508.2 & 9 \\
\hline SIMEC & 27 & nd & 219.6124 & 216.0 & 208.1 & 2208.4 & 10 \\
\hline KIMBERLY & 5 & 775.3 & 1112.1739 & 903.0 & 1708.9 & 1967.8 & 11 \\
\hline CONTINENTAL GRUPO & 7 & 339.3 & 590.3945 & 403.2 & 1017.1 & 1125.3 & 12 \\
\hline CORP. DURANGO & 12 & 115.2 & 330.3553 & 304.0 & 1089.9 & 927.7 & 13 \\
\hline MASECA & 8 & 338.7 & 609.1913 & 444.7 & 511.9 & 825.6 & 14 \\
\hline GIND SALTILLO & 9 & 313.4 & 435.9907 & 335.0 & 738.0 & 808.4 & 15 \\
\hline CEMENTOS CHIHUAHUA & 14 & 70.5 & 115.5706 & 98.5 & 395.2 & 774.4 & 16 \\
\hline SANLUIS CORPORATIVO & 11 & 116.2 & 164.7649 & 180.0 & 519.1 & 732.9 & 17 \\
\hline GEMBUNIDAS & 13 & 80.9 & 122.9281 & 120.3 & 290.8 & 706.7 & 18 \\
\hline HERDEZ & 10 & 210.4 & 297.1755 & 198.0 & 428.4 & 604.4 & 19 \\
\hline CMOCTEZUMA & 17 & 32.0 & 32.9863 & 28.7 & 249.7 & 594.2 & 20 \\
\hline ECKO & 18 & 14.5 & 38.2272 & 20.2 & 33.5 & 94.2 & 21 \\
\hline PARRAS & 15 & 61.7 & 69.3565 & 139.9 & 233.7 & 93.3 & 22 \\
\hline NUTRISA & 25 & nd & 8.0293 & 7.5 & 25.4 & 49.3 & 23 \\
\hline QB INDUSTRIAS & 19 & 10.0 & 3.8069 & 4.2 & 44.6 & 34.6 & 24 \\
\hline QUMMA & 26 & nd & 101.4704 & 56.8 & 52.7 & 32.3 & 25 \\
\hline MACMA & 24 & nd & 22.129 & 21.3 & 19.5 & 19.7 & 26 \\
\hline IASASA & 22 & nd & 45.1973 & 26.8 & 43.7 & 10.4 & 27 \\
\hline
\end{tabular}

Nota: El ranking está ordenado según los valores de ingresos en el año 2007 y en forma descendente. nd: datos no disponibles

Fuente: Elaboración propia con base en datos de la BMV (2008).

Son 16 empresas de la muestra las que obtuvieron rentabilidades promedio del orden o superior a $10 \%$ en dólares durante el periodo de análisis. Dado que éste comprende los efectos de dos grandes crisis, y considerando los bajos niveles de tasa de 
Cuadro 5

Ranking de empresas (por patrimonio neto)

\begin{tabular}{|c|c|c|c|c|c|c|c|c|}
\hline \multicolumn{9}{|c|}{ Patrimonio neto (millones de dólares) } \\
\hline Empresa & Ranking 1994 & 1991 & 1994 & 1995 & 2001 & 2002 & 2007 & Ranking 2007 \\
\hline CEMEX & 1 & 1832.1 & 4114.5 & 2911.0 & 6398.1 & 6144.1 & 14948.C & 1 \\
\hline GMODELO & 3 & & 2096.3 & 1417.5 & 3369.4 & 3452.4 & 5777.1 & 2 \\
\hline COCA COLA & 9 & & 457.4 & 281.7 & 794.7 & 901.7 & 4501.8 & 3 \\
\hline AlFA & 4 & 1700.7 & 1822.9 & 1414.3 & 1959.5 & 2078.4 & 3498.0 & 4 \\
\hline BIMBO & 6 & 688.8 & 1166.4 & 841.4 & 1356.4 & 1359.4 & 2557.4 & 5 \\
\hline $\mathrm{ICH}$ & 16 & 40.1 & 105.9 & 78.7 & 335.9 & 437.9 & 1636.6 & 6 \\
\hline GRUMA & 8 & 251.4 & 596.7 & 342.0 & 987.3 & 949.5 & 1437.9 & 7 \\
\hline SIMEC & 14 & & 312.4 & 188.3 & 303.6 & 348.5 & 1361.5 & 8 \\
\hline AHMSA & 5 & 1349.0 & 1550.4 & 1047.8 & 644.4 & 557.3 & 1352.0 & 9 \\
\hline CEMENTOS CHIHUAHI & 13 & 150.2 & 318.9 & 236.6 & 430.7 & 452.4 & 955.5 & 10 \\
\hline KIMBERLY & 7 & 729.6 & 1079.0 & 799.2 & 1263.6 & 1139.2 & 858.9 & 11 \\
\hline CMOCTEZUMA & 18 & 63.9 & 97.2 & 115.4 & 386.8 & 437.2 & 814.5 & 12 \\
\hline CONTINENTAL GRUPO & 15 & 238.8 & 303.5 & 197.3 & 637.8 & 668.1 & 763.1 & 13 \\
\hline VITRO & 2 & 1913.1 & 2111.3 & 1363.3 & 629.3 & 591.3 & 679.8 & 14 \\
\hline MASECA & 12 & 180.9 & 400.8 & 297.9 & 521.1 & 506.0 & 595.0 & 15 \\
\hline GIND SALTILLO & 10 & 327.7 & 421.0 & 296.4 & 473.3 & 452.0 & 550.3 & 16 \\
\hline CORP DURANGO & 11 & 228.0 & 411.4 & 290.7 & 810.8 & 426.0 & 422.2 & 17 \\
\hline GEMBUNIDAS & 21 & 66.2 & 87.1 & 74.6 & 116.2 & 113.4 & 233.7 & 18 \\
\hline HERDEZ & 23 & 58.1 & 31.5 & 79.3 & 164.8 & 153.5 & 184.5 & 19 \\
\hline SANLUIS CORPORATII & 20 & 128.6 & 88.0 & 65.0 & 61.2 & 61.6 & 107.0 & 20 \\
\hline ECKO & 25 & 29.4 & 26.2 & 20.9 & 24.1 & 24.2 & 53.5 & 21 \\
\hline QUMMA & 17 & & 104.8 & 63.8 & 55.9 & 43.8 & 49.0 & 22 \\
\hline MACMA & 24 & & 26.3 & 24.4 & 20.2 & 17.5 & 15.8 & 23 \\
\hline NUTRISA & 26 & & 4.9 & 4.8 & 9.9 & 9.3 & 13.3 & 24 \\
\hline IASASA & 22 & 40.9 & 59.6 & 50.4 & 51.1 & 41.2 & 5.7 & 25 \\
\hline QB INDUSTRIAS & 27 & 6.9 & 2.6 & 2.1 & 35.9 & 30.1 & 3.0 & 26 \\
\hline PARRAS & 19 & 74.8 & 91.3 & 107.0 & 67.0 & 95.5 & -5.9 & 27 \\
\hline
\end{tabular}

Nota: El ranking está ordenado según los valores de ingresos en el año 2007 y en forma descendente. nd: datos no disponibles.

Fuente: Elaboración propia con base en datos de la BMV (2008).

interés del periodo, puede decirse que desde este punto de vista la estrategia resultó exitosa. Ello se relaciona con incrementos de ingresos y patrimonio significativos, ${ }^{21}$

21 En estos datos hay sesgos muy notorios como por ejemplo el caso de CEMEX, para la cual el cambio de patrimonio neto está obviamente subestimado, si se recuerda que esta empresa ha establecido subsidiarias en 52 países, lo que debe responder al modo en que cada firma organiza y contabiliza su tejido de compañías en el país y el exterior. 


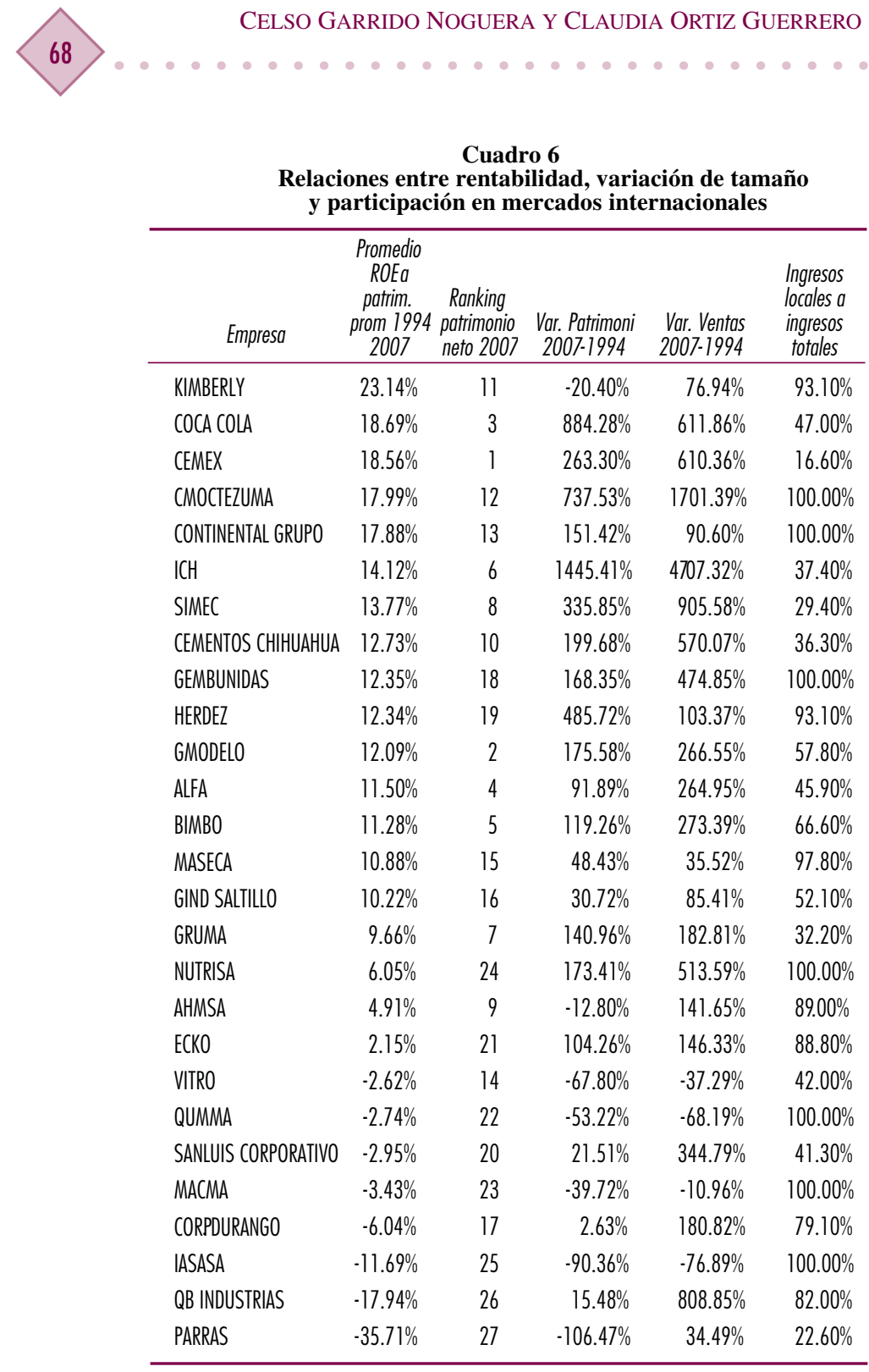

Nota: Los datos están ordenados en razón del promedio deROE.

Fuente: Elaboración propia con base en la BMv (2008).

y con el hecho de que todas las que participan en este segmento de rentabilidad ocupan los lugares superiores en el ranking de patrimonio para 2007. Finalmente puede señalarse que con excepción de Parras, en este grupo se encuentran todas las firmas para las cuales el mercado internacional representa $50 \%$ o más de sus negocios, lo que sugiere una correlación positiva con la rentabilidad. 
Por el contrario, 11 de las empresas en la muestra obtuvieron rentabilidades menores a ese valor o francamente negativa, lo que puede evaluarse como un indicador de resultados desfavorables de la estrategia. Con excepción de AHMSA, todas estas compañías están en los lugares más bajos del ranking de patrimonio y seis de ellas han visto reducir tanto dicho patrimonio como las ventas. Puede señalarse que la casi totalidad de este grupo tiene centrados sus negocios en el mercado interno, lo que sugiere que son firmas que no aplicaron estrategias de internacionalización comercial o productiva como las que antes esquematizamos, salvo los casos de Vitro y Parras. ${ }^{22}$

Todo lo anterior indicaría que las empresas que asumieron las estrategias de incrementar su tamaño mediante la internacionalización productiva habrían logrado un éxito razonable, pues no sólo sobrevivieron a la apertura sino que son más grandes $\mathrm{y}$ tuvieron una rentabilidad atractiva dadas las condiciones, mientras que las que crecieron limitadas al mercado interno han tenido desempeños desfavorables en rentabilidad a pesar de que en algunos casos tuvieron crecimientos significativos de patrimonio y ventas. En consecuencia, ello sugeriría una correlación positiva de la rentabilidad con respecto al tamaño y la internacionalización.

Sin embargo, este análisis debe complementarse con la consideración de tres factores de vulnerabilidad que enfrentan estas empresas, tanto las internacionalizadas como las centradas en el mercado interno.

El primero es resultante de la recurrente estrategia seguida por las GEM en cuanto a financiar su crecimiento con la emisión de deuda, particularmente en divisas, antes que con recursos propios. ${ }^{23}$ Con esa estrategia, las firmas buscarían combinar el atractivo del crecimiento con la capacidad de distribuir dividendos para los accionistas. ${ }^{24}$ Éste ha sido un factor recurrente de vulnerabilidad financiera de las GEM en las distintas crisis, y ello vuelve a presentarse como un problema preocupante en la actual coyuntura (véase el cuadro 7).

22 Para un estudio sobre la evolución y limitaciones de los cambios ocurridos en Vitro puede verse Garrido y Ortiz, 2008a.

23 Un caso notable de ello es cuando en medio de la crisis en enero de 2009 se produce por parte de Bimbo la sorprendente adquisición de Weston Foods Inc en Estados Unidos por un monto de 2,400 millones de deuda financiado casi en su totalidad mediante deuda. Véase http://olganza. com/2009/01/22/concluye-bimbo-adquisicion-de-george-weston-foods-de-eeuu/.

24 Esta estrategia de financiamiento contrasta con la seguida por las grandes empresas de los países desarrollados que se financian predominantemente con fondos propios como se muestra en Singh y Hamid (1992). Para un ejercicio en el que se demuestra esta proposición de que las grandes empresas mexicanas se financian predominantemente vía deuda puede verse Garrido y Ortiz (2008b) y Ortiz y Garrido (2008). 
Cuadro 7

Pasivo total a patrimonio neto

\begin{tabular}{lrrr}
\hline \multicolumn{1}{c}{ EmPRESA } & 1995 & 2002 & $2008^{\star}$ \\
\hline IASASA & 0.95 & 1.34 & 50.74 \\
SANLUIS CORPORATIVO & 4.92 & 10.09 & 6.16 \\
VITRO & 2.09 & 3.98 & 4.16 \\
CORP. DURANGO & 1.86 & 2.96 & 2.23 \\
CEMEX & 1.91 & 1.77 & 2.14 \\
KIMBERLY & 0.75 & 0.95 & 1.95 \\
AHMSA & 1.59 & 4.75 & 1.89 \\
ALFA & 2.05 & 2.42 & 1.84 \\
GRUMA & 2.23 & 1.34 & 1.48 \\
GEBUNIDAS & 0.60 & 1.16 & 1.36 \\
HERDEZ & 1.01 & 1.76 & 1.31 \\
GINDSALIILLO & 0.51 & 1.04 & 1.22 \\
CEMENTOS CHIHUAHUA & 0.43 & 0.95 & 0.96 \\
MACMA & 0.48 & 0.85 & 0.88 \\
QUMMMA & 0.90 & 0.97 & 0.80 \\
ICHB & 0.23 & 1.14 & 0.80 \\
BIMBO & 0.45 & 1.35 & 0.75 \\
SIMEC & 1.72 & 0.45 & 0.74 \\
COCA COLA & 1.35 & 0.77 & 0.68 \\
GMODELO & 0.47 & 0.63 & 0.60 \\
MASECA & 0.39 & 0.34 & 0.56 \\
EKCO & 0.70 & 0.63 & 0.41 \\
NUTRISA & 0.11 & 0.40 & 0.30 \\
CONTINENTAL GRUPO & 1.09 & 0.27 & 0.26 \\
CMOCTEZUMA & 0.08 & 0.25 & 0.16 \\
PARRAS & 0.96 & 3.17 & -8.65 \\
QB INDUSTRIAS & 1.29 & 1.46 & -41.50 \\
\hline & & & \\
\hline & & & \\
& & &
\end{tabular}

* Datos a octubre de 2008.

Fuente: Elaboración propia con base en la BMV (2008).

Como puede verse, en los periodos de crisis, como fueron 1995 y 2002, se registran niveles relativamente elevados de endeudamiento de un grupo significativo de empresas por montos que representan entre uno y 10 veces el patrimonio neto. En la actual coyuntura de crisis estas relaciones parecen presentarse en niveles más preocupantes, pues excluyendo a las que se hallan en una notoria situación de insolvencia, se observa que un tercio de las firmas de la muestra tiene deudas del orden de dos o más veces que su patrimonio neto.

Sin embargo, lo que es más significativo en la coyuntura actual es la estructura temporal de dichas deudas, como puede verse en el cuadro 8 .

\section{Desarrollo}


Cuadro 8

Estructura temporal de los pasivos

\begin{tabular}{|c|c|c|c|c|c|c|c|c|c|c|}
\hline \multirow{3}{*}{ Empresa } & \multicolumn{3}{|c|}{1995} & & \multicolumn{3}{|c|}{$2008^{*}$} & \multirow{3}{*}{$\begin{array}{l}\text { Ingresos } \\
\text { locales } \\
\text { a ingreso } \\
\text { total 2008* }\end{array}$} \\
\hline & $\begin{array}{l}\text { Pasivo } \\
M E C P\end{array}$ & $\begin{array}{l}\text { Pasivo } \\
\text { MN CP }\end{array}$ & $\begin{array}{c}\text { Total } \\
C P\end{array}$ & $\begin{array}{l}\text { Pasivo } \\
\text { ME CP }\end{array}$ & $\begin{array}{l}\text { Pasivo } \\
\text { MN CP }\end{array}$ & $\begin{array}{c}\text { Total } \\
C P\end{array}$ & $\begin{array}{l}\text { Pasivo } \\
M E C P\end{array}$ & $\begin{array}{l}\text { Pasivo } \\
M N C P\end{array}$ & Total CP & \\
\hline & \multicolumn{9}{|c|}{ Porcentaje } & \\
\hline \multicolumn{11}{|l|}{ CEMENTOS } \\
\hline CHIHUAHUA & 21.98 & 3.85 & 25.83 & 10.10 & 4.61 & 14.71 & 31.12 & 8.86 & 39.98 & 36.30 \\
\hline GEMBUNIDAS & 16.69 & 80.87 & 97.56 & 2.13 & 92.55 & 94.67 & 22.41 & 5.62 & 28.03 & 100.00 \\
\hline CEMEX & 28.18 & 1.76 & 29.94 & 35.45 & 4.86 & 40.31 & 36.97 & 10.39 & 47.36 & 16.60 \\
\hline VITRO & 21.11 & 10.62 & 31.73 & 35.46 & 11.30 & 46.76 & 26.32 & 28.00 & 54.32 & 42.00 \\
\hline ALFA & 34.40 & 13.05 & 47.45 & 32.01 & 14.47 & 46.49 & 25.38 & 31.80 & 57.19 & 45.90 \\
\hline SANLUIS & 61.76 & 6.02 & 67.78 & 19.60 & 7.10 & 26.71 & 0.09 & 50.93 & 51.02 & 41.30 \\
\hline HERDEZ & 53.00 & 44.91 & 97.90 & 0.55 & 45.13 & 45.68 & 62.12 & 14.14 & 76.26 & 93.10 \\
\hline COCA COLA & 15.99 & 8.81 & 24.80 & 1.12 & 43.83 & 44.95 & 25.56 & 30.87 & 56.42 & 47.00 \\
\hline GRUMA & 20.05 & 7.35 & 27.40 & 30.00 & 5.49 & 35.49 & 41.48 & 10.81 & 52.29 & 32.20 \\
\hline BIMBO & 46.70 & 37.00 & 83.69 & 20.69 & 9.78 & 30.47 & 34.67 & 29.63 & 64.30 & 66.60 \\
\hline KIMBERLY & 38.21 & 11.72 & 49.93 & 12.51 & 43.93 & 56.43 & 0.00 & 64.73 & 64.73 & 93.10 \\
\hline GIND SALTILLO & 22.58 & 29.12 & 51.70 & 10.74 & 20.80 & 31.54 & 6.27 & 51.38 & 57.64 & 52.10 \\
\hline ECKO & 36.43 & 28.57 & 65.00 & 13.19 & 41.03 & 54.21 & 39.08 & 20.07 & 59.15 & 88.80 \\
\hline QUMMA & 18.76 & 48.53 & 67.29 & 13.93 & 65.04 & 78.97 & 11.07 & 3.35 & 14.41 & 100.00 \\
\hline MACMA & 2.21 & 46.70 & 48.91 & 7.66 & 85.60 & 93.27 & 3.77 & 22.89 & 26.66 & 100.00 \\
\hline CORP DURANGO & 39.62 & 9.67 & 49.30 & 77.36 & 8.45 & 85.81 & 1.25 & 98.75 & 100.00 & 79.10 \\
\hline AHMSA & 27.65 & 9.53 & 37.18 & 7.84 & 91.22 & 99.06 & 1.07 & 35.29 & 36.36 & 89.00 \\
\hline CONTINENTAL GRUPO & 1.14 & 46.21 & 47.34 & 1.16 & 98.84 & 100.00 & 20.93 & 57.87 & 78.80 & 100.00 \\
\hline MASECA & 15.22 & 61.60 & 76.82 & 36.74 & 63.26 & 100.00 & 52.40 & 41.20 & 93.60 & 97.80 \\
\hline ICHB & 48.40 & 51.60 & 100.00 & 21.74 & 78.26 & 100.00 & 36.71 & 13.47 & 50.18 & 37.40 \\
\hline PARRAS & 42.33 & 28.91 & 71.24 & 22.36 & 8.50 & 30.86 & 3.36 & 61.36 & 64.72 & 22.60 \\
\hline CMOCTEZUMA & 59.94 & 40.06 & 100.00 & 11.21 & 88.79 & 100.00 & 12.53 & 34.43 & 46.96 & 100.00 \\
\hline QB INDUSTRIAS & 0.00 & 99.48 & 99.48 & 63.03 & 36.97 & 100.00 & 43.90 & 17.52 & 61.42 & 82.00 \\
\hline GMDELO & 13.67 & 86.33 & 100.00 & 6.08 & 93.92 & 100.00 & 0.00 & 96.32 & 96.32 & 57.80 \\
\hline SIMEC & 48.57 & 6.98 & 55.56 & 63.94 & 36.06 & 100.00 & 1.64 & 67.89 & 69.53 & 29.40 \\
\hline IASASA & 17.80 & 50.95 & 68.74 & 11.40 & 72.96 & 84.36 & 0.00 & 77.74 & 77.74 & 100.00 \\
\hline NUTRISA & 0.00 & 100.00 & 100.00 & 0.00 & 100.00 & 100.00 & 0.00 & 75.69 & 75.69 & 100.00 \\
\hline
\end{tabular}

Nota: ME: moneda extranjera. MN: moneda nacional. CP: corto plazo. LP: largo plazo.

* Datos a octubre de 2008

Fuente: Elaboración propia con base en la BMV (2008).

De acuerdo con esta información, la mayoría de las empresas tienen una parte principal de su deuda contratada a corto plazo, y adicionalmente un segmento importante la tiene contratada en moneda extranjera. La situación es más vulnerable para aquellas compañías que operan centralmente en el mercado interno, pues ello significa que sus ingresos son en moneda local por lo que han sufrido el impacto de la fuerte devaluación del peso desde fines de 2008 sobre su deuda externa de corto plazo. En consecuencia, estas firmas enfrentan un problema de fragilidad financiera que podría agravarse tanto por las fluctuaciones del tipo de cambio como por la contracción de 
las operaciones en sus mercados, ya sean locales o internacionales. ${ }^{25}$ Algunas de estas empresas ya han hecho público que enfrentan problemas financieros, llegando incluso a iniciar procesos de concurso mercantil como en el caso de Corporación Durango, ejemplo que es probable sea seguido por otras entidades en los próximos meses.

A esto se suma la evolución adversa que han tenido algunas empresas respecto al manejo de sus coberturas de riesgo cambiario mediante la contratación de productos financieros derivados de lo que se informa en el cuadro 9.

\begin{tabular}{lrrrrr}
\multicolumn{6}{c}{ Cuadro 9 } \\
\multicolumn{5}{c}{ Derivados (millones de dólares) } \\
\hline AHMSA & 2004 & 2005 & 2006 & 2007 & $2008^{*}$ \\
\hline ALFA & 0.00 & 0.00 & 2.30 & 0.33 & 6.05 \\
BIMBO & 0.00 & 0.00 & 5.89 & 7.69 & 360.16 \\
CEMEX & 0.00 & 0.00 & 2.69 & 0.00 & -7.28 \\
GIND SALTILL & 0.00 & 142.73 & 13.27 & 36.04 & 250.06 \\
GRUMA & 4.62 & 0.56 & 5.44 & 3.04 & 9.11 \\
ICHB & 0.00 & 0.00 & 2.33 & 2.34 & 312.82 \\
KIMBERLY & 0.00 & 0.00 & 0.00 & 0.00 & 10.25 \\
COCA COLA & 0.00 & 47.75 & 52.26 & 7.38 & 6.23 \\
MASECA & 0.00 & 20.66 & 33.05 & 11.35 & 16.76 \\
SIMEC & 0.00 & 0.00 & 0.00 & 0.00 & 2.27 \\
VITRO & 0.00 & 0.00 & 0.56 & 0.00 & 10.24 \\
& 0.00 & 11.83 & 12.45 & 79.63 & 247.34 \\
\hline
\end{tabular}

* Datos a octubre de 2008.

Fuente: Elaboración propia con base en la BMV (2008).

Como ha ocurrido en algunos casos, estos contratos se hicieron apostando a la estabilidad del peso, por lo que la reciente devaluación ha implicado un doble efecto perjudicial porque con ella se incrementa el costo de la deuda externa al tiempo que sufre la pérdida por la cobertura. Evidencias recientes de los impactos adversos que genera esta exposición a deuda son las reducciones de calificación en la calidad crediticia que han sufrido firmas altamente internacionalizadas como CEMEX y Bimbo. ${ }^{26}$

Un segundo factor de vulnerabilidad que enfrentan sobre todo las empresas con un componente importante de operaciones internacionales es el que resulta de la

25 Parte de estas situaciones parecen estar siendo cubiertas por NAFIN al otorgar a algunas empresas préstamos contra colaterales hipotecarios. Vitro recurrió a este programa a mediados de noviembre de 2008.

26 Véase Alonso (2009) y Editorial (2009).

\section{Desarrollo}


previsible contracción de los mercados externos, lo que habrá de presionar sobre su situación financiera sin que el mercado interno pueda compensar estas caídas de ventas dada la situación deprimida en la que se encuentra la demanda interna.

Un tercer factor de vulnerabilidad para este conjunto de GEM es de carácter estratégico y se deriva del modelo de organización productiva con que enfrentaron la competencia internacional mediante la expansión de sus principales líneas de producción basadas en productos tradicionales para mercados maduros. Esta actividad la han prolongado a lo largo de más de 15 años, sin explorar nuevas fronteras de negocios que alimenten dinámicas de crecimiento de ganancias de largo plazo con base en nuevas capacidades competitivas. ${ }^{27}$ En consecuencia, es previsible que en el contexto de un incremento de la competencia que acompañará al desarrollo de la actual crisis, estas firmas verán erosionadas sus utilidades y en consecuencia enfrentarán nuevas amenazas a la sostenibilidad de sus negocios.

\section{Conclusiones}

Como se demuestra en el trabajo, la actual crisis representa un punto de inflexión importante en el largo arco del cambio de la organización económica y de las GEM en México, iniciado hace más de 15 años, haciendo que — tras las apariencias de éxito pregonado por los defensores del modelo- afloren los desequilibrios y rezagos con los que ha operado la economía y las GEM. En principio, el segmento inmediatamente vulnerable lo representa el sector externo dado el importante nivel de los déficit comerciales, pues una coincidencia entre la caída de las exportaciones manufactureras - junto a la pérdida de ingresos por la disminución del precio del petróleo, la contracción de las remesas y de capitales de corto plazo- puede traducirse en una crisis externa y ampliar la crisis cambiaria. La capacidad del mercado interno para compensar la caída de la demanda externa es limitada, tanto por el largo proceso de deterioro de la demanda interna inducida por la reforma como por las restricciones para financiar importaciones en un contexto como el actual.

Desde el punto de vista de la situación de las GEM, la perspectiva con que enfrentan la actual crisis, debido al modo en que han financiado sus estrategias de crecimiento, crea la posibilidad de quiebras o por lo menos la reducción de los niveles de actividad, con impacto sobre la dinámica de producción y el empleo. Además haber

27 El cambio en el portafolio de negocios es una decisión riesgosa pero posible como lo demuestra el proceso de Dupont pero también algunos chaebol coreanos, véase Barton y Deustch (2008). 
decidido crecer con base en productos de mercados maduros limitan las posibilidades de que las GEM exploren caminos de innovación para desarrollar capacidades competitivas de largo plazo como forma de enfrentar la crisis. Y asumir que se debe enfrentarla como una inflexión de la cual se saldrá hacia las condiciones previas representaría un error de graves proporciones, pues sólo se alimentaría una profundización de los aspectos regresivos en la actual situación.

Por el contrario, es posible reconocer que la crisis crea una oportunidad para atacar la forma de organización económica y empresarial generada con las reformas, que es lo que en última instancia hace tan vulnerable la situación nacional frente a la crisis global. Desarrollar políticas para corregir dicha organización de la economía y de las GEM —al hacer que las políticas contracíclicas abran caminos a procesos de trasformación con el impulso de la economía de la innovación y el conocimiento en los segmentos donde el país tiene ventajas, y desarrollar PYME eficientes mediante la integración de cadenas productivas - son caminos necesarios para que la salida de la crisis sea al mismo tiempo la construcción de condiciones para un desarrollo sostenido. Sin duda que todo ello representa un enorme esfuerzo no exento de riesgos, pero parece un desafío imprescindible de asumir por el conjunto de los actores, porque la opción es enfrentar un panorama sombrío de estancamiento y atraso, aun para los que hasta ahora han sido los principales beneficiarios de las reformas, como ha sido el caso de las GEM, que según los resultados de este análisis se enfrentan a sus debilidades estructurales con riesgo de desaparecer o ser absorbidas por otras firmas del país o el exterior.

\section{Bibliografia}

Alonso, Ramiro, "A la baja, calificación de Bimbo", El Universal, México, 24 de enero 2009.

Banco de México, Estadísticas económicas, México, BANXICO, 2008.

Barton, Dominique y Clayton Deutsch, "Transforming a South Korean chaebol", The Mckinsey Quartely, Shangai, septiembre de 2008.

Bolsa Mexicana de Valores, Hojas de balance de las empresas, México, BMV, 2008.

CEPAL, "La transformación productiva veinte años después", Santiago, CEPAL, 2008.

Chesnais, Francois, La mundialización financiera, Buenos Aires, Losada, 1999.
Excélsior, "Perder grado de inversión alejará a fondos de CEMEX", editorial, Excélsior, México 26 de enero 2009.

Fazzari, Steven, Piero Ferri y Edward Greenberg, "Cash flow, investment, and KeynesMinsky Cycles", Journal of economic \& organization, vol. 65, issue 3-4, 2008.

Garrido, Celso, "Las multinacionales mexicanas", en Las multinacionales latinoamericanas: sus estrategias en un mundo globalizado, Daniel Chudnovsky (ed.), Buenos Aires, FCE, 1999.

"Fusiones y Adquisiciones de grandes empresas en México durante los noventa", en Cuadernos de Desarrollo Productivo y 
Empresarial, Santiago, CEPAL, 2001.

, Desarrollo económico y procesos de financiamiento en México, México, Siglo XXI, 2005.

, Ricardo Padilla y Rogerio de Araujo, "Las multinacionales y la innovación tecnológica en la manufactura mexicana", en La innovación tecnológica en México, Río de Janeiro, Joao de Negri (ed.), IPEA, en prensa, 2008.

y Ramón Padilla-Pérez, "Cooperation for innovation in the manufacturing industry in Mexico", in Cooperation for innovation in five Latin America countries, Mario Cimoli and Annalisa Primi, Santiago, CEPAL, forthcoming, 2008.

y Claudia Ortiz, "Instituciones, actores y mercados en el cambio empresarial. El caso de Cemex y Vitro, en Primer seminario nacional de economía institucional, México, Universidad Autónoma Metropolitana, del 17 al 21 de noviembre de 2008a.

"Análisis de la evolución del endeudamiento de una muestra de grandes empresas manufactureras en México, 1990-2003”, en Foro de finanzas y Administración, México, Universidad Autónoma Metropolitana, 30 de septiembre de 2008b.

Giovanni Cozzi y Jan Toporowski, "The balance sheet approach to financial crises in emerging markets", Working Paper, núm. 149, Department of Economics School of Oriental and African Studies, London, University of London, october, United Kingdom, 2006.

Informes anuales de las empresas, México, varios años.
Instituto Nacional de Estadística, Geografía e Informática, Censos económicos, México, INEGI, varios años.

Katz, Jorge, "Cycles of Creation and Destruction of 'Social Capabilities' in Latin America?", in Meeting of experts on "FDI, technology and competitiveness", Geneva, UNCTAD, Palais des Nations, 8-9 de marzo de 2007.

Ortiz, Claudia y Celso Garrido, "Un modelo de deuda e ingresos de una muestra de 14 grandes empresas manufactureras en México", en Tercer foro de investigación de matemáticas aplicadas a las ciencias sociales. Reflexiones sobre educación y matemáticas, México, Universidad Autónoma Metropolitana, julio de 2008.

Peres, Wilson y Giovanni Stumpo (coord.), Pequeñas y medianas empresas en América Latina y el Caribe, México, Siglo XXI, 2002.

Singh Ajit y Javed Hamid, "Corporate financial structures in developing countries", in $T e$ chnical paper, núm. 1, IFC, USA, The World Bank, 1992.

UNCTAD, World investment report, Geneve, UNCTAD, 2000.

"US Economic classification policy committee, North American Industry Classification System", US, consultado 30 de noviembre, 2008: http://www.census.gov/eos/www/ naics/

Williamson, John, "What Washington Means by Policy Reform?", Washington, DC, Institute of international economics, 1989. 